\title{
"A study to assess the knowledge and attitude of nurses regarding management of patient with depression in a selected general hospital at Tumkur, Karnataka"
}

\author{
Pushpendra Kumar ${ }^{1}$, Shoba B ${ }^{2}$ \\ Assistant professor, Arawali College of Nursing, Sikar \\ Professor, Sridevi College of Nursing, Tumkur
}

\begin{abstract}
Depression is one of the common and most affected worldwide public health problems. Depression is an illness that not only involves the mood and thought of a person but also the whole body. Depression is a major cause for premature death and disabilities throughout the world. The high prevalence of suicide is closely associated with depression. Every person usually suffers with depression during their life time. But the degree may be from mild to severe.

Method: The research approach used for the study was descriptive survey approach and the research design selected for the study was non experimental descriptive research design. The pilot study was conducted with 10 samples and the reliability of tool was established by rater and inters rater method for the main study 100 samples of nurses were selected by the convenient sampling technique. A structured questionnaire was used to assess the knowledge and attitude of nurses regarding management of patients with depression. The reliability coefficient for knowledge was 0.78 and for attitude was 0.96. The correlation value of knowledge and attitude was found to be 0.86. which is reliable.

Results: The data were analyzed by using descriptive and inferential statistics .the mean score of the knowledge was 14.33 with standard deviation5.61 and the mean score for the attitude was found 15.61 with standard deviation of 5.77. The study findings revealed that majority of nurses60\% demonstrated inadequate knowledge and majority $56 \%$ of nurses exhibited unfavorable attitude towards the management of depressive patients. A significant relationship was found between and attitude as the obtained coefficient of correlation value (r).957 was significant at 0.05 level. This suggests that nurses who had lower score in knowledge questionnaire also had lower score in attitudes questions.

Interpretation and conclusion: From the study findings it is clearly depicted that nurses knowledge regarding management of patient was found inadequate and attitude was found unfavorable and also found that selected demographic variables such as sex, general education, work area and position of a nurse in the hospital had no significant relationship, and variable such as experience and in-service education program had shown significant relationship with their knowledge and attitude.

Key Words: - Depression, Premature Death and disabilities, Suicide.
\end{abstract}

\section{Introduction:-}

Everyone experience variations in Mood, blues that come and go, disappointment, the normal grief that accompanies the loss of someone you love. A depression is an illness that involves the body Mood and thoughts and it is not a sign of personal willful condition that can be willed or wished away. ${ }^{1}$

Depression is a disease that affect majority of public in the world wide as a survey 450 million people suffer from mental disorder out of that 121 million people suffer with depression in the world. ${ }^{2}$ It has been predicted that by 2020 depression will be second most common cause of death and disability worldwide ${ }^{3}$

Depression affects many people of all age. It is estimated that one in five people will suffer from depression some point during their lives. More than $80 \%$ of those suffering from depressive illness can be treated successfully with modern medication and proper Management. ${ }^{1}$

It is estimated that 18.8 Million American (9.5\% of U.S. population), over the age of 18, suffer from depressive disorder. Five percent of U.S. population suffers from severe depressive disorder, for women that is about $21 \%$, and for men it's $12 \%$ so there is almost a two-time greater risk of depression in women. ${ }^{4}$

Major depression is the fifth top reason for loss of reproductive life throughout world. Depression ranks first among causes of disability in the Americans and top $5^{\text {th }}$ of every other world region except Africa where it is ranked $11^{\text {th }} .5$

In India about 55 million people suffer with psychiatric disorders, depression is one of them. Even there are about 42 mental hospitals in India. In spite of the high burden of mental disorders most people in India do not have access to mental healthcare due to inadequate facilities and lack of human resources. India has 0.25 mental health beds per 10,000 populations. Of these, the vast majorities $(0.20)$ are in mental hospitals and are occupied 
by long-stay patients; therefore it is very difficult to access by the general population. India has merely 0.4 psychiatrists, 0.04 psychiatric nurses, 0.02 psychologists and 0.02 social workers per 100,000 populations. ${ }^{6}$

Suicide, which is as important cause of premature death, is strongly associated with depression. ${ }^{7}$

The current trends where earlier depression patient were treated only in psychiatric hospital are now admitted and treated in general hospital. Due to very less number of trained psychiatric nurses, a large number of nurse having, ANM, GNM are directly employed in psychiatric unit which creates lots of insecurity of herself as well as for other patient.

Knowledge and attitude of nurse play very important role in rendering care to patient, adequate knowledge helps the nurse to recognize the early symptoms of depression and provide needed care to the patients which helps patients in early recovery. Hence the investigator is interested to explore the knowledge and attitude of nurses regarding management of patient with depression.

\section{OBJECTIVES OF THE STUDY}

1. To assess the knowledge and attitude of nurses regarding management of patient with depression.

2. To determine the relationship between knowledge and attitude of Nurses.

3. To determine the association of knowledge and attitudes of nurses with selected demographic variables.

4. To distribute information guide sheets to nurses regarding management of patient with depression.

\section{RESEARCH HYPOTHESES}

$\mathrm{H}$ : There will be a significant association of knowledge and attitude of nurses regarding Management of patient with depression with selected demographic variables.

\section{Methods And Materials}

The research approach used for the study was descriptive survey approach and the research design selected for the study was non experimental descriptive research design. The pilot study was conducted with 10 samples and the reliability of tool was established by rater and inters rater method for the main study 100 samples of nurses were selected by the convenient sampling technique. A structured questionnaire was used to assess the knowledge and attitude of nurses regarding management of patients with depression. The reliability coefficient for knowledge was 0.78 and for attitude was 0.96 . The correlation value of knowledge and attitude was found to be 0.86 .which is reliable. The data were analyzed by using descriptive and inferential statistics.

\section{Results}

\section{Table 1}

Frequency and Percentage distribution of knowledge scores of nurses regarding management of patients with depression:

\begin{tabular}{cllcc}
\hline Sl. No. & Levels of Knowledge & Score range & Frequency $(\mathbf{f})$ & Percentage \\
\hline 1. & Inadequate & Below 50 \% Score (1-15) & 60 & 60 \\
2. & Moderate & $51-75 \%$ Score (16-22) & 30 & 30 \\
3. & Adequate & Above 75\% Score (23-30) & 10 & 10 \\
\hline
\end{tabular}

Table 1 shows that $60 \%$ of nurses had inadequate knowledge regarding management of patient with Depression followed that by $30 \%$ nurses had moderate knowledge and only $10 \%$ of nurses had adequate knowledge towards the management of patients with depression.

Table 2

Frequency and Percentage distribution of level of attitude of nurses regarding management of patients with depression:

\begin{tabular}{cllcc}
\hline Sl. No. & Levels of attitude & Score range & Frequency (f) & Percentage \\
\hline 1. & Unfavorable & Below 50 \% Score (1-15) & 56 & 56 \\
2. & Moderately favorable & $51-75 \%$ Score (16-22) & 29 & 29 \\
3. & Most favorable & Above 75\% Score (23-30) & 15 & 15 \\
\hline
\end{tabular}

The table 2 shows that $56 \%$ of nurses indicate their unfavorable attitude, following by $29 \%$ of nurses indicates their moderately favorable attitudes, and only $15 \%$ of nurses exhibited their most favorable attitude towards the management of patients with depression. 
Table 3

Relationship between knowledge and attitude

\begin{tabular}{lllllll}
\hline Domain & Mean & SD & Min & Max & Range & Mean\% \\
\hline Knowledge & 14.33 & 5.616 & 06 & 26 & 20 & $47.76 \%$ \\
Attitude & 15.61 & 5.77 & 08 & 27 & 19 & $52.03 \%$ \\
\hline
\end{tabular}

The above table depicts the relationship between knowledge and attitude by mean, SD, Range, and mean $\%$. The knowledge score ranging from 6-26, in which mean value is $14.33(47.76 \%$ of mean percentage score), with a standard deviation of 5.61.The attitude score in above table ranges from 8-27, in which mean value is $15.61(52.03 \%$ of mean percentage score) with a standard deviation of 5.77.

Table 4

Correlation between knowledge and attitude

Correlation between Correlation coefficient

Knowledge and Attitude

$0.957^{* * * * *}$

The above table reveals that there is a significant positive correlation $(r=0.957)$ between knowledge and attitude of nurses.

Table 5

Association between knowledge of nurses with selected demographic variable.

\begin{tabular}{|c|c|c|c|c|c|c|c|c|}
\hline \multirow[t]{2}{*}{ Sl. No } & Demographic variables & \multicolumn{4}{|c|}{ Knowledge } & \multirow{2}{*}{$\begin{array}{c}\text { Chi-square } \\
\chi^{2} \\
\end{array}$} & \multirow[t]{2}{*}{ df } & \multirow{2}{*}{ Inference } \\
\hline & & $\leq \mathrm{Mec}$ & & $>\mathbf{m e}$ & & & & \\
\hline & & $\begin{array}{l}\text { No. } \\
\text { (51) }\end{array}$ & $\%$ & $\begin{array}{l}\text { No. } \\
\text { (4) }\end{array}$ & $\%$ & & & \\
\hline \multirow[t]{5}{*}{1} & Experience & & & & & & & \\
\hline & 1. 1-3 years & 10 & 10 & 15 & 15 & & & \\
\hline & 2. 4-7 years & 20 & 20 & 10 & 10 & 8.778 & 3 & S \\
\hline & 3. $8-10$ years & 16 & 16 & 11 & 11 & & & \\
\hline & 4. Above 10 years & 5 & 5 & 13 & 13 & & & \\
\hline
\end{tabular}

The data in above table indicate the association between experience and knowledge is significant at $<0.05$ level.

Table 6

Association between attitudes of nurses with selected demographic variable

\begin{tabular}{|c|c|c|c|c|c|c|c|c|c|c|}
\hline \multirow{4}{*}{$\begin{array}{l}\text { Sl. } \\
\text { No } \\
\end{array}$} & \multirow{2}{*}{ Demographic variables } & \multirow{2}{*}{\multicolumn{2}{|c|}{ Sample (n) }} & \multicolumn{4}{|c|}{ Attitude level } & \multirow{2}{*}{$\begin{array}{c}\text { Chi } \\
\text { square } \chi \\
\end{array}$} & \multirow[t]{3}{*}{ df } & \multirow[t]{2}{*}{ Inference } \\
\hline & & & & & & & & & & \\
\hline & & 100 & $\%$ & \multicolumn{2}{|c|}{$\leq$ Median } & \multicolumn{2}{|c|}{$>$ median } & & & \\
\hline & & & & No. (50) & $\%$ & $\begin{array}{l}\text { No. } \\
(50)\end{array}$ & $\%$ & & & \\
\hline \multirow[t]{3}{*}{1} & In service education & & & & & & & & & \\
\hline & 1. Yes & 7 & 7 & 1 & 1 & 6 & 6 & 3.840 & 1 & S \\
\hline & 2. No & 93 & 93 & 49 & 49 & 44 & 44 & & & \\
\hline
\end{tabular}

The data in above table indicate the association between in service education program and attitude is significant at $<0.05$ level.

Majority $91(91 \%)$ of the nurses were female and very less (9\%) were male. Most of staff nurses $(87 \%)$ were G.N.M., $8 \%$ were PCBSc(N), and only $5 \%$ had professional qualification of BSc. $(\mathrm{N})$. With regard to age maximum number of nurses $31(31 \%)$ were in the age group 26-30 years and, 26(26\%) were in the age group of 31-35 years, and 25(25\%) of them were in age group of $21-25$ years and 18(18\%) were above the age of 35 years. Education wise majority of subjects $(93 \%)$ had a general education $12^{\text {th }}$ standard. With respect to working area majority of (27\%) staff nurses were working in general ward. With respect to position majority of nurses $(87 \%)$ were staff nurses, $8 \%$ were ward in charge, and only $5 \%$ of them were head nurses. Majority of nurses had experience of 4-7 years (30\%), 27\% had an experience of $8-10$ years, 25\% of them had an experience of 1-3 years, and $18 \%$ of nurses had an experience of above 10 years. About $93 \%$ of subjects have not attended inservice program, $7 \%$ of subjects had attended the in-service program on depression. 
In the study it was observed that out of 100 subject majority $60(60 \%)$ of staff nurses were having inadequate knowledge with Mean score 14.33(SD 5.61).With regard to overall attitude out most 56(56\%) of staff nurses exhibited unfavorable attitude with a Mean score of 15.61(SD 5.77).

There was positive correlation between knowledge and attitude of nurses regarding management of patient with depression resulted to be positive that is $r=0.957$ which is statistically significant at $p<0.05$ value .The correlation between the different aspects of knowledge and attitude invariably significant. There was significant association between knowledge with selected demographic variables such as age, professional education, experience and in service education program of nurses at the $\mathrm{p}<0.05$ level. There was significant association between attitude with selected demographic variables such as experience and in service education program of nurses at $\mathrm{p}<0.05$ level. Information guide sheet containing information related to knowledge and attitude were distributed to nurses to enhance their knowledge and also to develop a positive attitude.

\section{Discussion}

The findings were discussed in relation to the objectives, need for the study, related literature of the study. The present study was conducted to assess the knowledge and attitude of nurses regarding management of patient with depression in a general hospital at Tumkur, Karnataka

The present study showed that the knowledge of nurses was inadequate. This supports the study which was conducted by Bruh $1 \mathrm{KG}$, in 2007 in Netherlands to assess knowledge of nurses and nursing assistants about recognition of depression and compared with DSM -IV diagnosis of depression. The finding revealed that recognition of depression by nurses and nursing assistants is low. ${ }^{8}$

Findings of the present study showed that the staff nurses had unfavorable attitude towards the depressive patients. This supports the finding of Reed F, Fitzgerald L who conducted a study in 2005 to assess the attitudes of nurses who were caring for people with depression. A qualitative descriptive study was used. Two groups of participants were selected, one group had education and support from mental health nurses and other group did not. It found that education and support influence nurses ability to provide care, other was found to have fear and avoidance towards depressive patients. ${ }^{9}$

A significant relationship was found between the score of knowledge and attitude. The correlation co efficient value was found to be 0.957 . This suggests that nurses who had low score in knowledge also had low score in attitude. This is supported by the study conducted by Furegato AR in 2009 in Brazil. The main aim of the study was to compare knowledge and opinion of two groups of nurses about depression. Result showed that No significant differences occurred between two groups neither in relation to the knowledge nor in their opinion about depression (Med 7.0 and 7.3). Nevertheless, it was observed lack of specific knowledge, need of updating, lack of experience and unawareness of the importance of their therapeutic role for depressed patients. Finding reveals that both group showed deficit of knowledge and unawareness about importance of their therapeutic role in depression. ${ }^{10}$

In this study there was significant association found between knowledge of nurses with selected demographic variables like age, professional education, and professional experience. There was also association found between the attitudes of nurses with selected demographic variables such as experience and in service education program. This supports the finding of MC Launghlin who conducted a study in 1994 where he found that older and more experienced nurses had positive attitude towards depression than younger and less experienced nurses towards suicide. This also supports the finding of Walt and Gillis (1979) whose finding showed that custodial attitude were held predominantly by staff nurses with less training, while more liberal and nontraditional attitude were more prevalent among trained nurses. ${ }^{11}$

\section{Recommendations}

On the basis of the findings of the study the following recommendations were made:

- Similar study can be conducted with fewer samples with different demographic characteristics.

- An experimental study can be conducted.

- A similar study can be conducted with even large sample and different hospitals.

- A comparative study can be done on nurses' knowledge and attitude working in other special areas and psychiatric ward.

- A similar study can be conducted to explore the knowledge and attitude of parents or relatives of depressive patients.

\section{Acknowledgement}

I acknowledge with deep gratitude the guidance and support offered by my principal Prof.K.Ramu. I am thankful to my guide Prof.Sheeba.B. for her guidance throughout my study. I am grateful to the experts for being kind enough to spend their time carefully reading my tool and providing insightful comments. 


\section{Reference}

[1]. Rethink, Depression: introduction and symptoms, 2008. www.enotalone.com/article/3093.html.

[2]. World health Report, world Health organization Geneva, Switzerland. 2001.

[3]. Walsh L., improving the care of patient with symptoms of depression, nursing Times, 2006 Feb 14-20; 102 (2): 28-30.

[4]. Introduction to depression, 2008 Sep.http:iml.jou.ufi. edu/projects/Fall04/Berry/introduction.html

[5]. Stress and Depression. Archives of Psychiatric Nursing.2005 feb;19(1): 18-19.

[6]. Sumitra Pathara, statistics on psychiatric professional. http:// infochangingindia.org.

[7]. Kabede D, Alem A Major Mental disorder in Addis Abada Ethiopia II Affective disorder. Journal of Acta psychiatric scandnavica 1999; 347(100): 18-23.

[8]. Bruh 1 KG., Lui jendi jk HJ, Muller MT., Nurses' and nursing assistants recognition of depression in elderly Journal of American Medical Director Association 2007 Sep; 8(7): 441-5.

[9]. Reed F, Fitzgerald L., The Mixed attitudes of nurses' caring for people with Mental illness in a rural general hospital. International journal of Mental Health Nursing 2005 Dec; 14(4): 249-57.

[10]. Furegato ar,ferreire da silva candido mc,lobo da costa m.comparing knowledge and openions on depression among nurses in the health services.rev salud pblica(bogota).2009 march-april;11(2):200-211.

[11]. Martin Anderson BA, nurse's attitude towards suicidal behavior. Journal of advanced nursing 1977 June, 25(6): 1283-1291 